\title{
Retro-Analysis of Rehabilitation of Existing Bridge over the River Cubículo on Federal Highway BR-101, Brazil
}

\author{
Iviane Cunha e Santos ${ }^{1}$, Fábio Pessoa da Silva Nunes ${ }^{1}$ and Thyala Anarelli Cunha e Santos ${ }^{2}$ \\ 1. Road Directory, National Department of Transportation Infrastructure, Brasilia 70.040-902, Brazil \\ 2. Post-Graduate Program in Structures and Civil Construction, University of Brasilia, Brasilia 70.910-900, Brazil
}

\begin{abstract}
This work describes the retro-analysis of design of rehabilitation of existing bridge over the river Cubículo on BR-101 in Santa Catarina, Brazil, aiming to evaluate the intervention processes. In this way, it was verified that the project adopted for strengthening of the structure was not adequate to support the evolution of the maximum load over time and the overload due to widening, and it was also verified that the changes in the load factor do not comply with the update of the Brazilian Technical Standards ABNT: NBR-7188 [1]. The retro-analysis of the bridge rehabilitation project has demonstrated fundamental importance to avoid possible design failings, accidents, and reworks. Affirming that it is essential to comply with Standards and Technical Manuals on the elaboration of the rehabilitation project of structures and in choosing the type of intervention to the existing structure.
\end{abstract}

Key words: Maintenance, rehabilitation, widening, and strengthening.

\section{Introduction}

The current management of infrastructure is of concern worldwide.

Throughout the life of the existing infrastructure, its behavior must be continuously monitored, allowing the early detection of signs of changes in structural safety levels and functional performance. This is essential to operate and maintain efficiently and effectively, allowing for a repair schedule and cost-effective management.

According to The Bridges Manual of the DNIT (National Department of Transportation Infrastructure) [2], the designed structures should be lightweight, aesthetic and elegant, on the other hand, it must be sufficiently robust to provide comfort to the user and be usable over of throughout life, without exceptional maintenance, rehabilitation or strengthening.

However, due the significant increase in the volume of traffic on federal highways, the lack of proper maintenance and aging of bridges in the infrastructure

Corresponding author: Iviane Cunha e Santos, Ph.D. candidate, research fields: bridges, dynamics and numerical model. system, which in the great majority are dated from the $60 \mathrm{~s}$, the bridges present inadequate feedback to the current load conditions, becoming critical points, those responsible for the bottlenecks and the occurrence of accidents.

The maintenance deficiency is the main reason for structural damage, increasing the speed of degradation and compromising the safety of users, Vitório [3].

As reported by Mendes [4], current scenario of the 5,600 bridges registered in the System of Management of Bridges of the DNIT is arranged as follows:

- $70 \%$ of the bridges are over 30 years old;

- $79 \%$ of bridges have an overall width less than 40 feet, considered narrow by current standards; and

- $90 \%$ of the bridges were designed with a load of 40.46 and 26.98 tons.

Thus, it can be concluded that most existing bridges need to be adapted, improving serviceability structural and/or functional.

In this sense, the article describes the retro-analysis of the project of rehabilitation of the bridge over the river Cubículo on Federal Highways BR-101 in Santa Catarina, Brazil. In these cases, the bridge work was 
programmed as an improvement project and the rehabilitation exceeds the scope of normal maintenance, including strengthening, and widening of the original structure.

\section{Case Study-Bridge over River Cubículo}

Fig. 1 shows the location of the bridge over the River Cubículo on BR-101 in Santa Catarina, Brazil.

As part of an expansion project was built a dual Highway on BR-101. The update includes two lanes in each direction and a new bridge over the river Cubículo, as shown the layout in Fig. 2.

The case study was the rehabilitation of the existing bridge that was not originally predicted in the construction contract. Thus, the rehabilitation work presented a financial impact of R \$ 574,173.66 (Brazilian Price Reference August 2003), which represents an increase of $6.245 \%$ in relation to the value of the original contract.

The project was developed by the Projectors Group STE/VEGA/DYNATEST/ENGER responsible for supervising the construction together with The Local Unit of the DNIT. The construction took place under the contract established between the DNIT and the Constructor Group SOGEL/CONTESA.

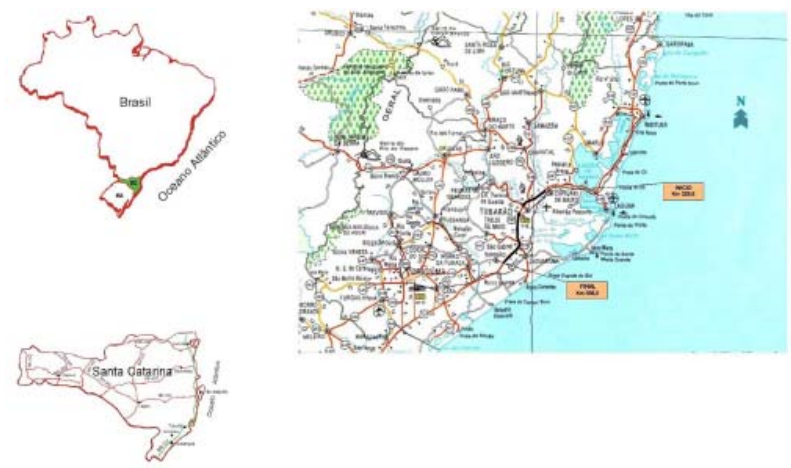

Fig. 1 Location of the River Cubículo Bridge.

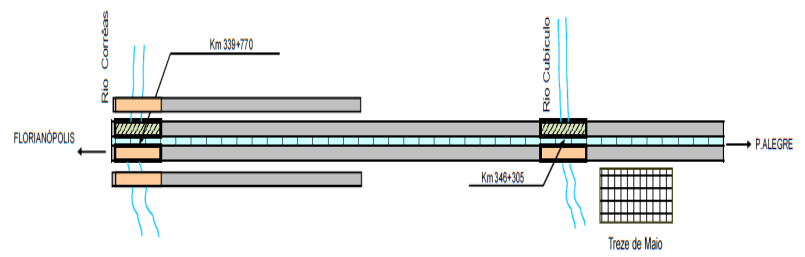

Fig. 2 Schematic of the dual Highway on BR-101.

\subsection{Original Structure}

The original structure was designed and built in the 60s and contemplates design truck of $80.000 \mathrm{lb}$, Brazilian Standard ABNT: NBR-7188 [5]. Fig. 3 presents the pictures of the bridge over the River Cubículo, bottom view and top view, where you can visualize the dual Highway on BR-101.

The reinforced concrete bridge features two side spans of $11.67 \mathrm{ft}$., a central span with $17.67 \mathrm{yd}$. and two cantilever spans of $8.28 \mathrm{yd}$., totaling $42 \mathrm{yd}$. The superstructure consists of a concrete box girder with a width of $11.11 \mathrm{yd}$., where $9.11 \mathrm{yd}$. of deck and two sidewalks of $3 \mathrm{ft}$. each.

The pier in the form of short columns with rectangular section 9.84 in. thick and 6.11 yd. wide, supported by foundations whit solid blocks and steel piles. The bearing type Freyssinet supported the superstructure. Fig. 4 shows the lateral and cross section of the bridge.

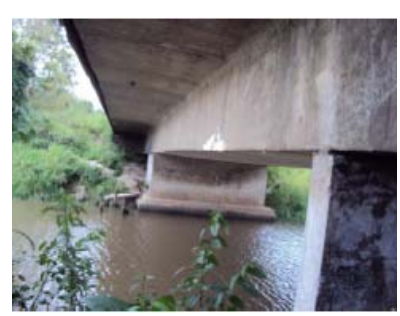

(a)

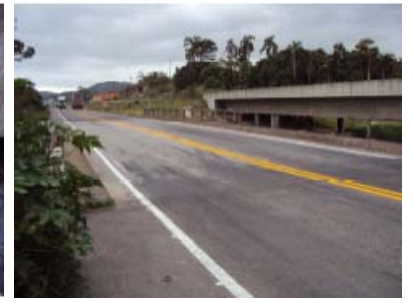

(b)
Fig. 3 Bridge River Cubículo (a) bottom and (b) top View.

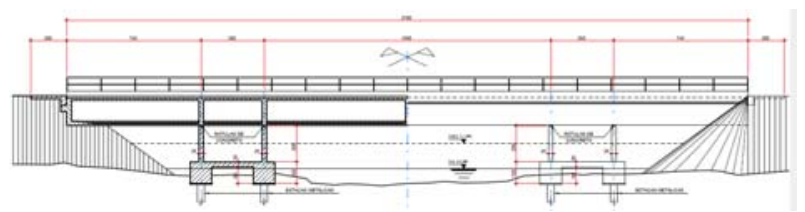

(a)

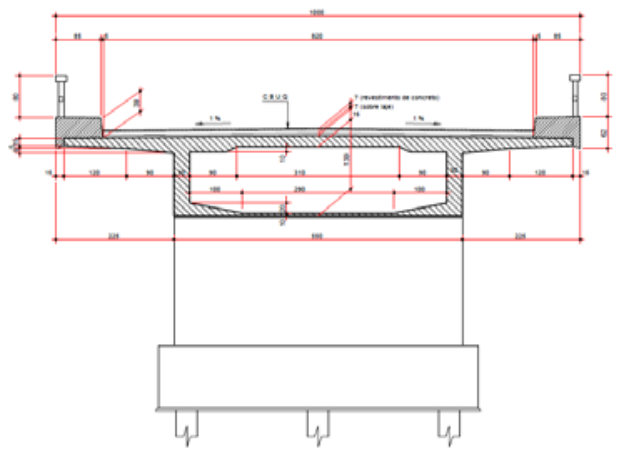

(b)

Fig. 4 The original design: (a) lateral and (b) cross section. 


\subsection{Rehabilitation: Strengthening and Widening Design}

For purpose rehabilitation was planning to improving serviceability structural and functional, strengthening and widening.

The project was planned to widen the structure to the final section of $13.44 \mathrm{yd}$. width, compound by $12.56 \mathrm{yd}$. of roadway width and two barriers with $1.33 \mathrm{ft}$. each, removing the sidewalks.

The need for strengthening arises from deterioration, modification in use and change in design code ABNT: NBR-7188 [1] to adapt to the design truck for 49.60 tons.

Thus, the project proposed a complement of 2.76 in. thick slab on the original structure to accommodate reinforcing bars with in-situ concrete, strengthening box girder by adding external post-tensioning, to repair and strengthen concrete bridge piers and an additional foundation. Fig. 5 presents the details of the design.

The strengthening considered the reinforced concrete of 4,350 psi. for the superstructure and 2,900 psi. in the piers and foundation.

\section{Bridges Loads and Load Factors}

In Brazil, the minimum requirements for loads and forces, load factors, and load combinations used for the design of bridges are specified in Brazilian Standard ABNT: NBR-7188 [1].

The bridges until 1950 were design according to Brazilian Standard from 1946, which provided for a load composed of a compressor of 53,954 lb. and a truck of 20,232 lb. per lane, and uniformly distributed load of 0.65 psi. and the load factor of $\phi=1.3$.

Between 1950 and 1960, the Brazilian Standards did not suffer revisions. Nevertheless, there was the evolution of the Standards for Roads Design, where the vehicle was composed of a compressor of 53,954 lb. and a truck of 26,977 lb. by lane and a uniformly distributed load of 0.73 psi. with load factor of $\phi=1.3$.

Between 1960 and 1975, there were major changes in the Brazilian Standard, the main one was the introduction of the design truck consisting of 80,000 lb.,

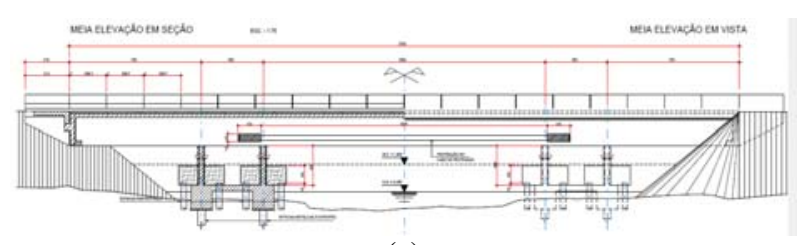

(a)

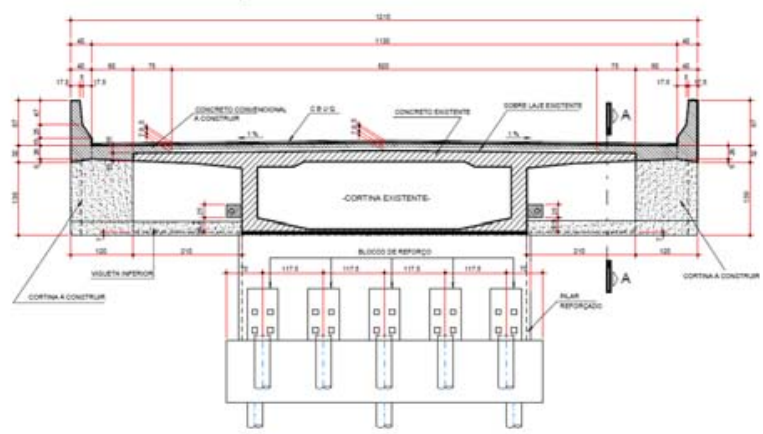

(b)

Fig. 5 Bridge Strengthening: (a) lateral and (b) cross section.

uniformly distributed load of 0.73 psi. in front and behind the truck and a 0.44 psi on the rest of the deck and on the sidewalks, the load factors were given in the function of span by the formulation $\phi=1.4-0.007 \mathrm{~L}$.

Between 1975 and 1985, the design code was updated in 1984 Brazilian Standard ABNT: NBR-7188 [5]. The main changes during this period were the introduction of the design truck with 101,164 lb. and uniformly distributed load of 0.73 psi. The design truck made up of a $10-\mathrm{ft}$. wide by $20-\mathrm{ft}$. in length and of uniformly distributed load of intensity of 0.73 psi for the deck and p of 0.44 psi for the sidewalks.

The loads for the bridges were divided into three classes by weight of the design truck: Class 45 (450 kN) of 101,164 lb., Class 30 (300 kN) of 67,442 lb. and Class $12(120 \mathrm{kN})$ of 26,977 lb. However, all the bridges on Federal Highways System are scaled in Class 45, and the other classes for secondary roads.

In 2013, the main modification in the Brazilian Standard ABNT NBR-7188 [1] was the Load Factors and the prediction of the need for specific studies for the dynamic amplification of structures with spans greater than $222.22 \mathrm{yd}$. With the update the load factors were made by combination of three equations which shown below, as defined in Eq. (1), for the concentrated loads, and Eq. (2), for the distributed loads: 


$$
\begin{gathered}
Q=P \times C I V \times C N F \times C I A \\
q=p \times C I V \times C N F \times C I A
\end{gathered}
$$

where, $Q$ is the final concentrated static load plus all the load factors, $P$ is a concentrated static load with a static value of wheel load, $q$ is the uniformly distributed static load plus all the load factors; $p$ is the uniformly distributed static load.

The $C I V$ is the vertical impact factor that amplifies the static load simulating the dynamic effect of the live load, however, it does not eliminate the need for dynamic analysis in sensitive structures with low stiffness, e.g. steel bridges, cable-stayed bridges, and suspension bridges. $C I V$ is defined per Eq. (3):

$$
\begin{gathered}
\mathrm{CIV}=1,35 \rightarrow \mathrm{L}_{\mathrm{Vão}}<10 \mathrm{~m} \\
\mathrm{CIV}=1+1,06 \times\left(\frac{20}{L_{i v}+50}\right) \rightarrow 10 \leq \mathrm{L}_{\mathrm{Span}}<200 \mathrm{~m} \\
\operatorname{CIV}=(\text { Especific studies }) \text { para } \mathrm{L}_{\text {Span }}>200 \mathrm{~m}
\end{gathered}
$$

where, $L_{S p a n}$ is the length of spans in meters, for isostatic structures, or the arithmetic median of length of spans, in cases of continuous spans.

$C N F$ is the factor of the number of traffic lanes and relates the probability that the live load simultaneously occurs, Eq. (4) defines the factor $C N F$ :

$$
C N F=1-0,05 \times(n-2)>0,9
$$

where, $n$ is the number of traffic lanes.

The additional impact factor CIA consists of increasing the live load due to the imperfection or discontinuity of the deck, structural joints, edges, transition structures and accesses, defined per Eq. (5):

$$
\begin{gathered}
\text { CIA }=1,25 \rightarrow \text { Concret and Mixes Structures } \\
\text { CIA }=1,15 \rightarrow \text { Steel Structures }
\end{gathered}
$$

The condition of use CIA is limited only to the sections of the structural elements with horizontal distance to the joint less than $5.56 \mathrm{yd}$. for each side of the joint or structural discontinuity.

\subsection{Loads on the Bridge over the River Cubiculo}

The analysis of the bridge model aimed to evaluate the change of the loads coming from the update of the Brazilian Standard of 1960 ABNT: NBR-7188 [5] for ABNT: NBR-7188 [1], where truck design from 80,000 lb. to $101,164 \mathrm{lb}$. and consequences of the load increase due to widening. Table 1 shows the changes of the loads obtained considering the original condition of the project of 1960 and the current loading condition.

In accordance with the requirements of ABNT: NBR-7188 [1], there is an increase in the intensity of the loads acting on the bridge in $64.46 \%$ for the concentrated loads and $31.53 \%$ for the loads distributed, in relation to the original load for which the structure was designed.

This increase in the values of the loads observed in the practical case is not only due to the load factor that went from 1.3 to 1.71 , but also due to the increase in the value of the design truck going from $80,000 \mathrm{lb}$. to 101,164 lb.

\section{Methodology}

For the analysis and verification of the project proposal for the rehabilitation of the bridge over the river Cubículo, the numeric model of the superstructure was developed and simulated in two different situations: the first in the original condition relating to the original loads and the structure response to the current loads, and the second in relation to the proposed strengthening and widening with the loads according to Brazilian Standard ABNT: NBR-7188 [1].

The simulation objective was to analyze the LSD (Limit State Design), where the proposed project for strengthening and widening should meet two main criteria: ULS (Ultimate Limit State) and SLS (Serviceability Limit State). The results were to compare with the limits established in current regulations.

\subsection{Numeric Model of Original Structure}

The numerical model was developed in the Software ANSYS version R15, considering the bridge deck as a

Table 1 Calculation of concentrated and distributed loads.

\begin{tabular}{ll}
\hline Original load & Current load \\
\hline$\varphi=1.30$ & $C I V=1,368 ; C N F=1,0 ; C I A=1,25$ \\
$P=11,240 \mathrm{lb}$. & $P=16860 \mathrm{lb}$. \\
$p=0.73 p s i$. & $p=0,73 p s i$. \\
$Q=14612 \mathrm{lb}$. & $Q=P \times C I V \times C N F \times C I A=28,830 \mathrm{lb}$. \\
$q=8.45 p s i$. & $q=p \times C I V \times C N F \times C I A=1.248 p s i$. \\
\hline
\end{tabular}




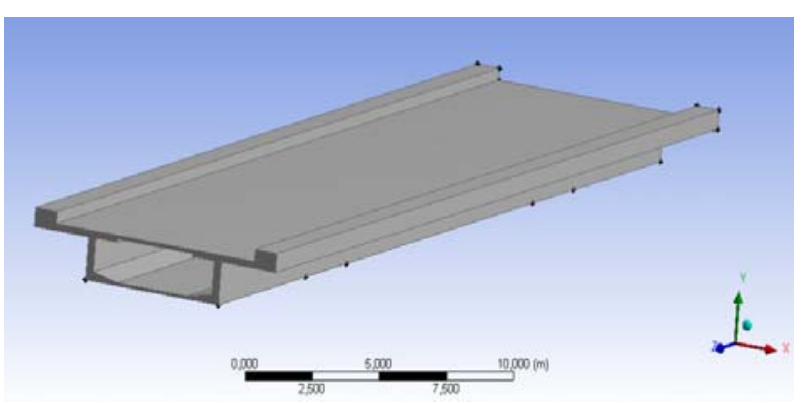

Fig. 6 Solid 3D numerical model—original structure.

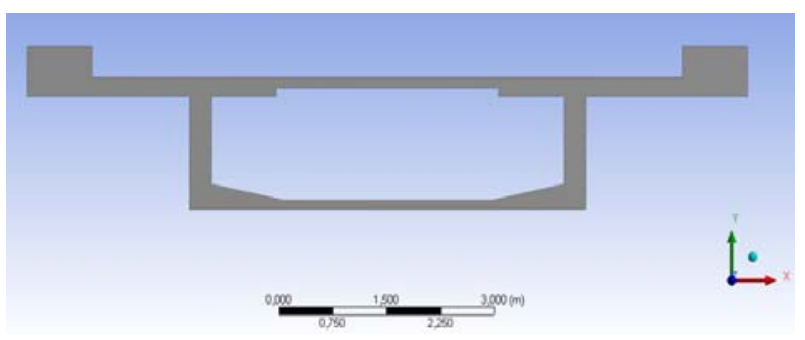

Fig. 7 Detail of the 3D solid deck—original structure.

solid element, adopting the element SOLID187, a quadratic element with 10 nodes and three degrees of freedom per node. This element was selected to represent the deck due to the capacity of analysis in the nonlinear regime. Figs. 6 and 7 respectively present the global model and details of the 3D solid element model.

\subsection{Numeric Model of Rehabilitation}

The deck was modeled as solid element, adopting the element SOLID187, where the sections of widening and the additional beams were considered, as proposed in the project. Figs. 8 and 9 show, respectively, the global model and the details of the model.

Two load steps were considered in the non-linear analysis, in the preliminary the loading of the external post-tensioning of box girder were considered composed with the dead load, and finally the live loads.

\section{Results}

The results are presented separately, first the original structure and then the proposal of rehabilitation. Finally, presents a parallel of the evaluation of the project proposal that subsidized the Technical Opinion.

\subsection{The Original Structure}

The first step was the static analysis considering the actions of the dead loads in the original structure. Fig. 10 shows the final deformation.

The second step was performed the transient analysis considering the actions of the live loads, that consists of a series of moving concentrated loads that vary in magnitude and spacing simulating vehicle movement on the structure. Fig. 11 shows the final deformation and stress.

Thus, we can verify that the original structure considering the live loads according standards presenting a low deformation in the middle span of approximately 1.18 in and stress of the order of 1,754 psi.

In addition, considering the live load in compliance to ABNT: NBR-7188 [1], the structure shows low deformations 3.15 in and stress 1,841 psi., as presented in Fig. 12.

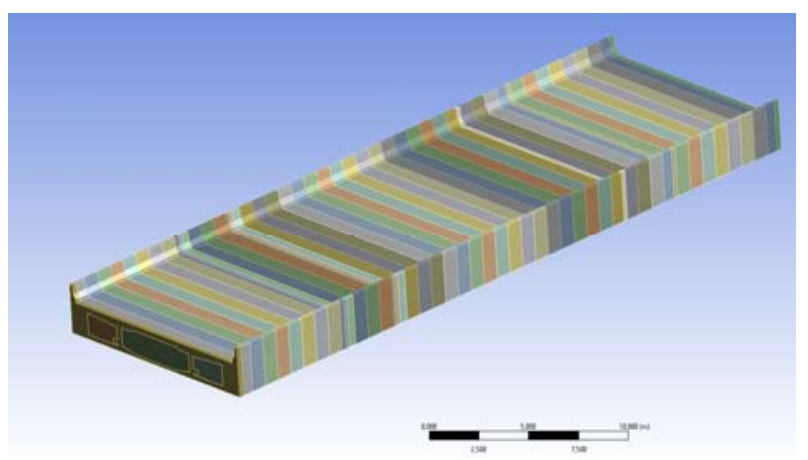

Fig. 8 Solid 3D numerical model—rehabilitation.

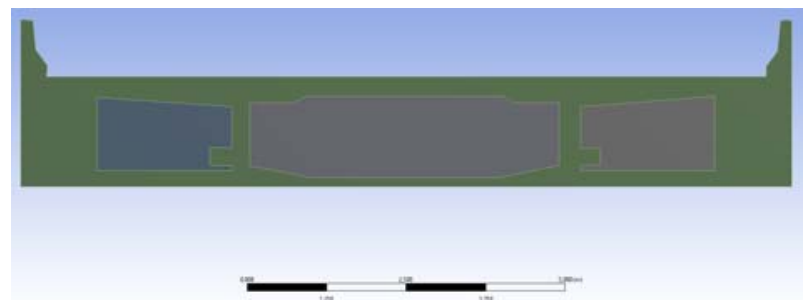

Fig. 9 Detail of the 3D solid deck-rehabilitation.

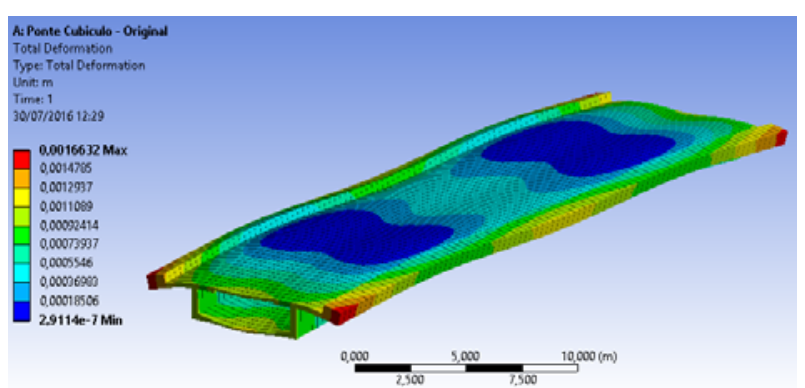

Fig. 10 Static analysis-final deformation. 

Federal Highway BR-101, Brazil

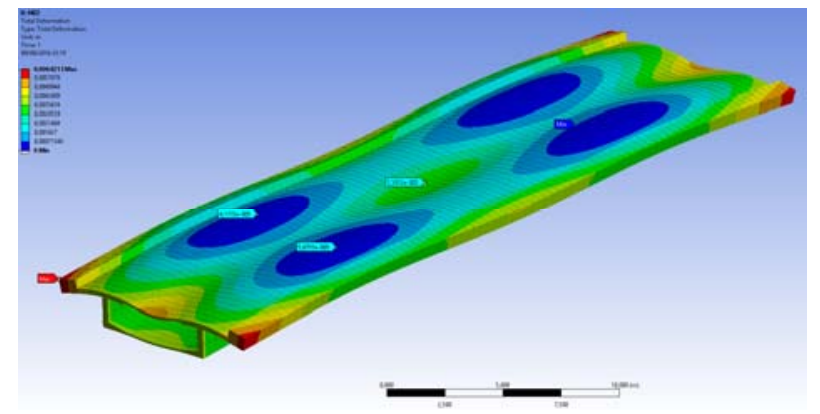

(a)

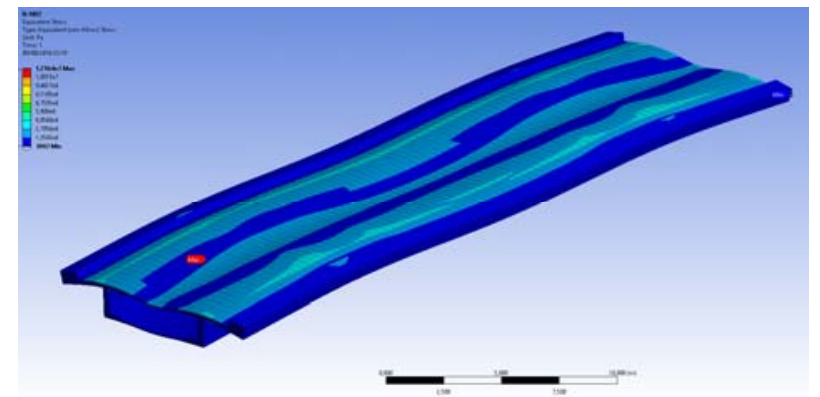

(b)

Fig. 11 Transient analysis (a) deformed shape and (b) stress.

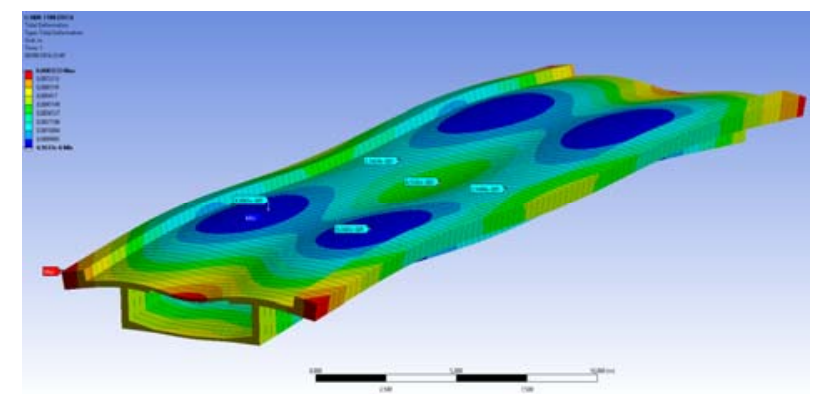

(a)

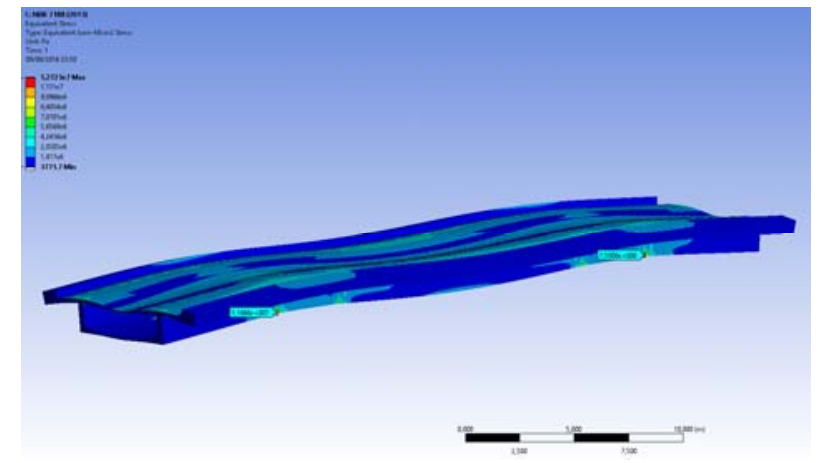

(b)

Fig. 12 Transient analysis (a) deformed shape and (b) stress.

The bridge behavior can be justified by the safety factor used in the design codes according to Brazilian Standards from 60s.

\subsection{Rehabilitation: Strengthening and Widening}

The static analysis considering the external post-tensioning of box girder according to the design and action of the dead loads were evaluated in the first stage. Fig. 13 shows the final deformation result found.

In the second stage, it was evaluated the final deformed with the superposition of the actions of the live load under the final deformation of static analysis.

Fig. 14 shows the results of the transient analysis.

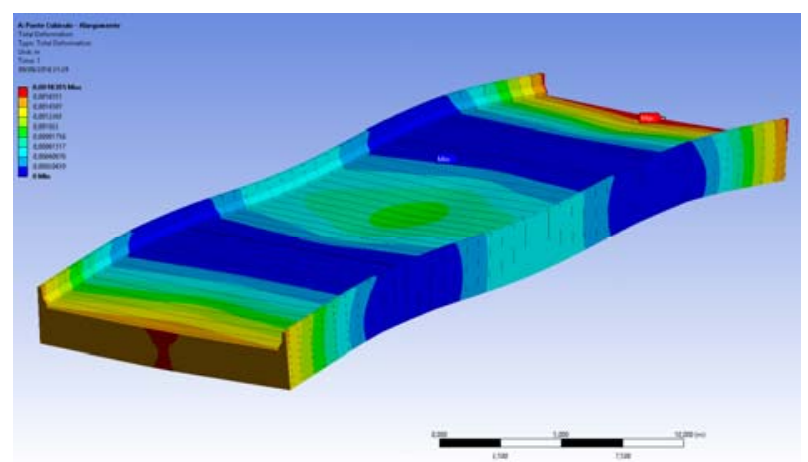

Fig. 13 Static analysis-final deformation.

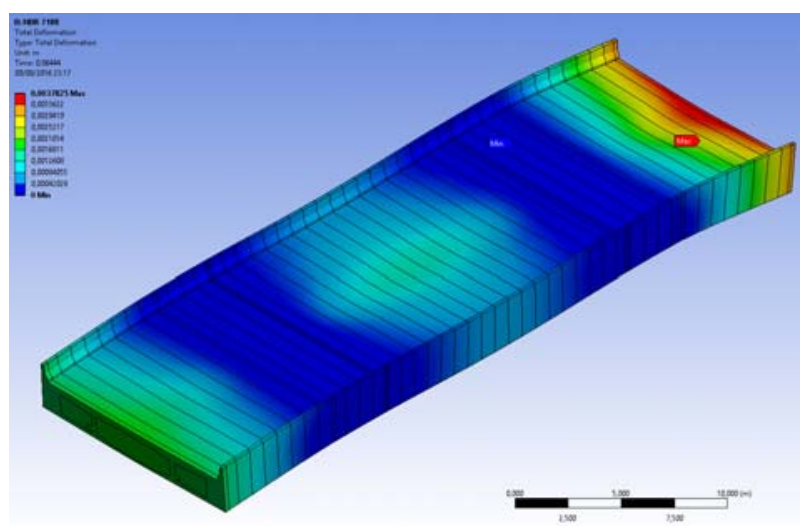

(a)

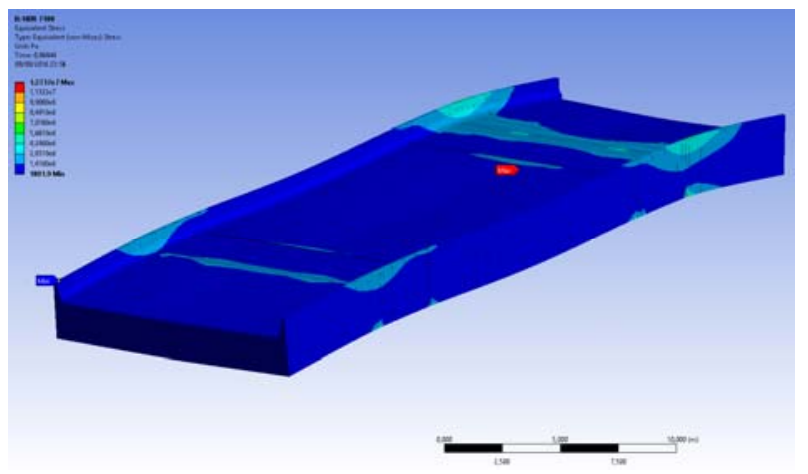

(b)

Fig. 14 Transient analysis (a) deformed shape and (b) stress. 
The proposal of rehabilitation presented low deformations 1.57 in and stress 1,847 psi.

\subsection{Evaluation of the Rehabilitation}

The proposed rehabilitation of the bridge did not present a final deformation higher than the limits established in the Brazilian Standard ABNT: NBR-6118 [6].

However, analyzing the maximum equivalent stress safety, that is based on the maximum equivalent stress failure theory, also referred to as the von Mises-Hencky theory, where a combination of principal stresses causes failure if the maximum equivalent stress $\left(\sigma_{e}\right)$ in a structure equals or exceeds a specific stress limit $\left(S_{\text {Lim }}\right)$, defined in Eq. (6):

$$
\frac{\sigma_{e}}{S_{\text {Lim }}}<1
$$

Considering that the failure is defined by material yielding, Eq. (7) limits the maximum equivalent stress to be less than the yield strength $\left(S_{y}\right)$ of the material:

$$
\frac{\sigma_{e}}{S_{Y}}<1
$$

The fracturing occurs when the maximum equivalent stress reaches or exceeds the ultimate strength of the material $\left(S_{u}\right)$ according to Eq. (8):

$$
\frac{\sigma_{e}}{S_{U}}<1
$$

The safety factor $\left(F_{S}\right)$ and the safety margin $\left(M_{S}\right)$ of the project is calculated per Eqs. (9) and (10) respectively.

$$
\begin{gathered}
F_{S}=\frac{S_{\text {Lim }}}{\sigma_{e}} \\
M_{S}=F_{S}-1=\frac{S_{L i m}}{\sigma_{e}}-1
\end{gathered}
$$

Thus, we can verify that the proposed rehabilitation of the bridge presented low values safety margin when compared to the stress limit of the material as presented in Fig. 15.

The proposal presented values of the safety margin less than 1.0 at various points of the bridge as read in Fig. 15. However, the adequate selection of the type of stress

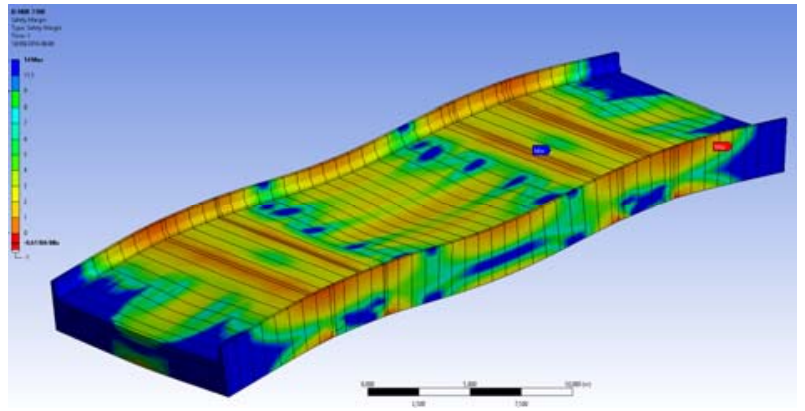

Fig. 15 The project margin of safety.

for each element analysis is fundamental for the correct judgment and application of the theory, as presented Juvinall [7] and Shigley \& Budynas [8].

\section{Conclusions}

Therefore, it was concluded that the proposal of project of rehabilitation of the structure was not adequate to support the change of the loads from updating the Brazilian Standard, and the consequences of overload due to widening. It can also be verified that the load factor according to the Brazilian Standard ABNT: NBR-7188 [1] was not considered in the project.

The retro-analysis of the bridge rehabilitation project has demonstrated fundamental importance to avoid possible design failings, accidents, and reworks. Affirming that it is essential to comply with Standards and Technical Manuals on the elaboration of the rehabilitation project of structures and in choosing the type of intervention to the existing structure.

The development of Technical Opinion on the proposed for rehabilitation of the bridge was based on the considerations of this study, and the project was rejected by the DNIT.

\section{Acknowledgment}

The authors would like to acknowledgement the following institution DNIT.

\section{References}

[1] ABNT: NBR-7188. 2013. Carga móvel rodoviária e de pedestres em pontes, viadutos, passarelas e outras estruturas. São Paulo: ABNT (Associação Brasileira de Normas Técnicas). 
[2] DNIT. 1996. Manual de Projeto de Obras-de-Arte Especiais. DNER (Departamento Nacional de Estradas de Rodagem), Rio de Janeiro.

[3] Vitório, J. 2002. Ponte Rodoviárias: Fundamentos, Conservação e Gestão. Recife: 1 Edição.

[4] Mendes, P. D. 2009. Contribuições para um modelo de gestão de pontes de concreto aplicada à rede de rodovias brasileiras. São Paulo, SP, Brasil: Escola Politécnica da Universidade de São Paulo, Departamento de Engenharia de Estruturas e Geotecnia.

[5] ABNT: NBR-7188. 1984. Carga móvel rodoviária e de pedestres em pontes, viadutos, passarelas e outras estruturas. São Paulo: ABNT (Associação Brasileira de Normas Técnicas).

[6] ABNT: NBR-6118. 2014. Projeto de estruturas de concreto-Procedimento. São Paulo: ABNT (Associação Brasileira de Normas Técnicas).

[7] Juvinall, R. C. 1967. Engineering Considerations of Stress, Strain, and Strength. Universidade de Michigan: Mcgraw Hill Series in Mechanical Engineering.

[8] Shigley, J. E., and Budynas, R. G. 2003. Mechanical Engineering Design, 7th edition. McGraw-Hill Science/Engineering/Math. doi: ISBN-13: 978-0072520361. 